\title{
Aportar, agradecer y adaptarse. Discursos históricos y representaciones sociales docentes sobre la diversidad migratoria
}

\author{
To contribute, thank and adapt. Historical discourses and teacher's social \\ epresentations about migratory diversity
}

\author{
Paula Luciana Buratovich \\ paulaburatovich@hotmail.com \\ Universidad de Buenos Aires, Argentina
}

Recepción: 12 Mayo 2021

Aprobación: 20 Octubre 2021

Publicación: 01 Noviembre 2021

Cita sugerida: Buratovich, P. L. (2021). Aportar, agradecer y adaptarse. Discursos históricos y representaciones sociales docentes sobre la diversidad migratoria . Anuario del Instituto de Historia Argentina, 21(2), e144.

https://doi.org/10.24215/2314257Xe144

\begin{abstract}
Resumen: Este artículo recorre el modo en el que la noción de instrumentalidad de la migración se presenta en los discursos de la élite política de la Argentina de fines del siglo XIX y principios del siglo $\mathrm{XX}$, señalando simetrías con aquellos que circulan entre los miembros de la institución educativa actual. Mediante una estrategia cualitativa basada en los principios de la Teoría Fundamentada, se analiza un corpus integrado por obras de autores como Ramos Mejía, Ingenieros y Rojas, como también una serie de grupos de discusión y entrevistas a docentes y directivos de escuelas primarias y secundarias del Área Metropolitana de Buenos Aires. La hipótesis de trabajo refiere a que es posible observar cómo determinados imaginarios presentes en aquellos discursos pueden rastrearse en las representaciones sociales de docentes y directivos, concebidos como agentes socializadores de una de las instituciones a través de las cuales el Estado administra la diversidad etno-nacional. Sin intención de realizar una imputación mecánica y determinista, el propósito es considerar que esos discursos, en tanto huellas históricas e ideológicas, tienen incidencia en la construcción de representaciones sociales acerca de la otredad y en la formación de vínculos interculturales signados en muchos casos por la discriminación y el prejuicio.
\end{abstract}

Palabras clave: Diversidad Migratoria, Discursos históricos, Escuela, Representaciones sociales, Interculturalidad.

Abstract: This article examines the way in which the notion of
instrumentality of migration is presented in the discourses of the
political elite of Argentina at the end of the 19th century and
the beginning of the 20th century, pointing out some similarities
with those that currently circulate among the members of the
school system. Through a qualitative strategy based on the
principles of Grounded Theory, a corpus made up of works
by authors like Ramos Mejía, Ingenieros and Rojas is analyzed,
as well as a series of focus groupsandin-depth interviews with
teachers and directors of primary and secondary schools of the
Buenos Aires Metropolitan Area. The hypothesis that guides
the investigation refers to the fact that it is possible to observe
how certain imaginaries present in those discourses can be
traced in the social representations of teachers and directors, 
conceived as socializing agents of one of the institutions through which the State administers ethno-national diversity. With the intention of avoiding a mechanical and deterministic analysis, the purpose is to consider that these discourses, as historical and ideological traces, have an impact on the construction of social representations about otherness and on the formation of intercultural links marked in many cases by the discrimination and prejudice.

Keywords: Migratory diversity, Historical discourses, School, Social representations, Interculturality.

\section{INTRODUCCIÓN}

Los modos en que se gestiona, nombra y representa la migración externa en un momento histórico determinado, aun cuando obedecen a una multiplicidad de variables, se inscriben en una serie histórica en la que ciertos imaginarios hegemónicos en el pasado perviven, resignificados y/o reactualizados, en forma de huellas históricas e ideológicas. Dicho de otra forma:si bien cada nación es artífice de sus propios relatos, tomando la célebre frase de Marx, "la tradición de todas las generaciones muertas oprime como una pesadilla el cerebro de los vivos".

En el caso argentino en particular, factores como el específico proceso de conformación y consolidación del Estado nación a fines del siglo XIX, el papel desempeñado por la élite cultural y política en esta tarea,y la forma en que la Argentina se representó a sí misma su lugar en el mundo han dejado su impronta en el modo en que hoy se experimenta la interculturalidad. Por lo tanto, un análisis integral de este fenómeno, ya sea a nivel del Estado y sus instituciones como desde la sociedad civil y otros actores, no puede eludir una mirada histórica que se pregunte por los cambios y las continuidades. ${ }^{[1]}$

En ese aspecto, un modo de concebir la migración externa ciertamente recurrente en la actualidad refiere a que esta debe ser tolerada a condición de que resulte conveniente, útil y funcional a la sociedad receptora, y evite trastocar su pretendida heterogeneidad e integridad(De Lucas, 2002). La escuela, en tanto institución del Estado, es uno de los espacios en los que es posible encontrar esta visión instrumental de la migración.

A través de la exposición de la categoría analítica "el migrante como instrumento", ${ }^{[2]}$ el objetivo de este artículo es reconstruir los discursos de algunos de los representantes de la élite política de fines del siglo XIX y principios del siglo XX (específicamente, a partir de un corpus de textos integrado por obras de José María Ramos Mejía, José Ingenieros y Ricardo Rojas), y señalar los puentes que pueden hallarse entre el modo en que allí se caracteriza la figura del migrante externo y las representaciones sociales que construyen docentes y directivos del Área Metropolitana de Buenos Aires de la institución educativa actual.

La estrategia metodológica llevada a cabo en la investigación en la que se inscribe este artículo combinó una serie de técnicas cualitativas como grupos de discusión, entrevistas en profundidad y análisis de textos. ${ }^{[3]}$

Se realizaron trece grupos que incluyeron a noventa y dos docentes seleccionados al azar entre docentes de nivel primario de escuelas públicas de gestión estatal y de gestión privada de Ciudad Autónoma de Buenos Aires y Gran Buenos Aires; y a docentes de nivel secundario del área de ciencias sociales, de escuelas públicas de gestión estatal y de gestión privada de CABA y GBA. Cada grupo, coordinado por una psicóloga especializada en dicha técnica, estuvo integrado por siete a diez docentes reunidos en una sala acondicionada con cámara Gesell. El instrumento utilizado fue una guía de pautas compuesta por preguntas generales capaces de funcionar como disparadores de diálogos sobre el concepto de diversidad cultural en el aula, su carácter problemático, las estrategias diferenciales para el tratamiento de la población migrante, su lugar en la escuela, su caracterización en términos de rendimiento escolar, de país de origen, de capacidad o intención 
de integración, como también de diferencias con respecto a los alumnos nativos. La guía se propuso plantear de modo velado los temas a discutir, de manera que llevase al tema sin contenerlo, "por la vía inconsciente del desplazamiento metonímico o de la condensación metafórica” (Ibáñez, 1992, p. 304). La discusión en grupo permitió acceder a una red de comunicación en la cual cada sujeto no constituye una unidad de información independiente de las demás, sino que integra un colectivo. Asimismo, se realizaron ocho entrevistas en profundidad semiestructuradas a docentes directivos de escuelas estatales de gestión pública de la CABA, para las cuales se empleó una guía de pautas semiestructurada —entendiendo por estructuración el grado de flexibilidad que tanto entrevistador como entrevistado tienen en la entrevista-, que partió de aspectos más generales acerca de la escuela hacia cuestiones más específicas sobre el vínculo entre segregación socio-espacial, presencia de migrantes y su desempeño escolar, como también sobre vínculos interculturales, función de la escuela en la integración de migrantes y el lugar de estos en la formación de la identidad nacional. De modo similar al grupo de discusión, esta técnica contribuye a conocer cómo los actores imaginan, interpretan y se representan sus propias experiencias y acciones.

La totalidad del material, incluido el corpus de textos de los representantes de la élite política de fines del siglo XIX y principios del siglo XX, se analizó siguiendo algunos de los lineamientos propuestos por la Teoría Fundamentada de Corbin y Strauss (2002) en lo que respecta a las operaciones de codificación abierta, axial y selectiva, procedimientos que permiten realizar un análisis integral construyendo categorías con gran densidad teórica, una de las cuales desarrollaremos en este trabajo.

\section{Estado NACIÓN y EXTRANJERIDAD EN LA Argentina}

La migración, al decir de Sayad (2008), es “la ocasión de realizar prácticamente, en el modo de la experiencia, la confrontación entre 'nacional' y 'no nacional'” (p. 102), y en la que surge, como una verdad irrefutable, la "no naturalidad" del vínculo del migrante con la comunidad a la que arriba, en oposición a la "naturalidad" del nativo. Esto instala de modo casi automático la sospecha sobre su figura, lo que justifica su control y vigilancia y erige su condición de extranjero casi por encima de cualquier otro atributo (Pacecca, 2001). En ese sentido, el migrante externo que arriba a una nación es extranjero en relación con los habitantes nativos de esta, condición relativa, pero a la vez es imbuido de extranjeridad, en tanto desde la sociedad receptora se le atribuyen características y señales identificatorias, con lo que se produce una reconstrucción de su subjetividad y una atribución de sentido a su presencia en el territorio nacional (Cohen, 2011). Esta extranjeridad, entonces, será resultado de un proceso en el que se intersecan la historia y pasado de la sociedad receptora, los rasgos del migrante (sobre todo, el modo en que estos son leídos) con el conjunto de representaciones que la sociedad receptora construye acerca de él.

Para analizarla debemos partir, como hemos señalado,de la especificidad del proceso de conformación del aparato estatal en la Argentina y del lugar asignado a la migración externa en este proyecto de "crear la nación” ${ }^{[4]}$ Siguiendo a Oszlak (2018), la entidad en formación (el Estado nación) va adquiriendo una serie de propiedades de estatidad para alcanzar distintos niveles de desarrollo. Se trata de una serie de categorías analíticas que nos permiten pensar el Estado nación en tanto relación social y aparato institucional a la vez. Una de ellas refiere "a su capacidad de diferenciar su control, a través de la creación de un conjunto funcionalmente diferenciado de instituciones públicas con reconocida legitimidad para extraer establemente recursos de la sociedad civil, con cierto grado de profesionalización de sus funcionarios y cierta medida de control centralizado sobre sus variadas actividades" (p. 16).Y otra, a su "capacidad de internalizar una identidad colectiva, mediante la emisión de símbolos que refuerzan sentimientos de pertenencia y solidaridad social y permiten, en consecuencia, el control ideológico como mecanismo de dominación" (p. 16).

Desde fines del siglo XIX y hasta 1914, la Argentina fue testigo de una extraordinaria expansión económica. Controladas las rebeliones civiles, superados los enfrentamientos entre facciones y lograda su expansión territorial definitiva gracias al efectivo y sanguinario proceso autodenominado "Conquista del 
Desierto", el Estado de 1880, finalmente y luego de un extenso y agitado proceso de disputas y acuerdos fallidos, logró un alcance nacional con un aparato institucional consolidado y una incorporación a la economía mundial — ligada a su rol de productor de materias primas_cada vez más profunda, por lo que la primera propiedad de estatidad descripta por Oszlak se encontraba prácticamente adquirida. La segunda, no obstante, empezó a constituirse en una preocupación para las clases dominantes locales.

En este contexto, el fenómeno migratorio se erige como una temática central, lo que no implica que sea novedoso. La historia muestra cómo los desplazamientos poblacionales se producen al margen de las voluntades de los gobiernos y las clases dirigentes, y que, más allá de su magnitud, cuantificación e importancia socioeconómica, se remontan a varios siglos atrás. HalperínDonghi (1976) indica que previamente a la Batalla de Caseros la inmigración sostenida ya se encontraba en marcha. Devoto (2003), por su parte, señala el año 1830 como punto de partida de una larga y sostenida migración europea, por lo que la caída de Rosas no representa en ese aspecto un punto de inflexión. Incluso, ya desde los años inmediatamente posteriores a 1810, desde el bando unitario surgen voces que ven en la inmigración un recurso eficaz para la prosperidad nacional. Ya hacia 1854 la mitad de la población económicamente activa de la ciudad está compuesta por extranjeros (HalperínDonghi, 1976).Sin embargo, lo que distingue al crecimiento de la segunda mitad del siglo XIX es que estuvo acompañado de una política estatal activamente pro-inmigratoria (Devoto, 2003). La élite después de Caseros vio en la migración no sólo un medio de agilizar el crecimiento demográfico y de obtener mano de obra, sino también la posibilidad de consolidar la influencia de Europa. El capital y el trabajo europeos, a través de la mejora de la población nacional mediante la mezcla, permitirían "crear una comunidad civilizada en el remoto rincón del mundo que es el Río de la Plata” (HalperínDonghi, 1976, p. 449).No obstante, esta misma élite que vio en la migración la solución a los problemas de la nación y la posibilidad de "germinar una nación moderna (...) en el desierto cultural y geográfico argentino" (Pacecca, 2001, p. 7), comienza, a fines del siglo XIX, a advertir las fisuras de su proyecto.

HalperínDonghi (1976) señala que esta diferencia entre expectativas y resultados se debe a que existía una fe apriorística en los beneficios de la inmigración, fundada en parte en la experiencia provista por la migración posterior a 1810, compuesta por una migración de élite no hispánica, poco numerosa y muy distinta de la migración de masas posterior. En coincidencia con esta apreciación, Pacecca (2001) considera que la caída de esta confianza plena en la migración también se debe a la "cita a ciegas' que con la inmigración europea tenían los sectores hegemónicos” (p. 7), ya que la figura del inmigrante contenida en la Ley 817 de Inmigración y Colonización (aprobada en el año 1876 y conocida posteriormente como Ley Avellaneda) está basada en una imagen fantasmática, en una idea, un proyecto, más que fundada en las características concretas de aquellos que vendrían. La percepción de la migración europea como portadora del progreso, no obstante, ha calado hondo en el imaginario nacional y se ha constituido en una representación que, como veremos, pervive hasta nuestros días.

La Argentina fue el país que mayor cantidad de población extranjera atrajo en relación con su población nativa. El censo de 1895 arroja que más de la mitad de los habitantes de la ciudad de Buenos Aires son extranjeros, en su mayoría italianos y españoles (Terán, 2008); y que los extranjeros representan ya el 25\% de la población total (Pacecca, 2001). La migración real, entonces, aceleró la constitución de la “cuestión nacional" como una preocupación central. Ante una sociedad heterogénea, con un Estado nación tardíamente consolidado y con una vasta presencia migratoria, urgía en la clase dirigente la necesidad de "fabricar" ciudadanos y construir una identidad nacional, avanzando en los niveles de estatidad referidos previamente. La escuela fue una de las instituciones protagonistas en esta ardua empresa. En su labor de producción y reproducción del modelo intercultural dominante (Cohen, 2009), la institución educativa fue clave en el establecimiento de "un sentido común acerca de lo que significa ser argentino" (Romero, 2004, p. 24), labor que continúa desempeñando en la actualidad. Sin embargo, este proceso no fue uniforme; la importancia atribuida a la escuela y la confianza depositada en su capacidad nacionalizadora fue directamente 
proporcional a la preocupación que la formación de la nacionalidad despertaba en las élites dirigentes en cada momento concreto de este proceso de configuración estatal (Bertoni, 2001).

Ante la constatación de que los migrantes no portaban únicamente aquella tan deseada laboriosidad, la alarma comienza a incrementarse. Los barcos que arribaban desde el "viejo" continente también traían ideologías políticas y experiencias sindicales y de lucha de clases. Ante esta crisis de expectativas (Devoto, 2003), las opiniones de la élite en torno a la migración, entonces, comienzan a teñirse de apreciaciones desde asimilacionistas hasta xenófobas, pese a que la insistencia en su potencial civilizador y modernizador no desaparece en absoluto. Frente a la posibilidad de la agitación plebeya, las propuestas desde el Estado y la élite fueron heterogéneas, pues el mito civilizador asociado a la inmigración "era casi más fuerte que los prejuicios" (Devoto, 2003). Así, las leyes de Residencia y Defensa Social, de 1902 y 1910 respectivamente, constituyen la respuesta represiva que, en articulación con la educación nacional, la reforma militar (mediante la instauración del servicio militar obligatorio) y la reforma política (instauración del voto obligatorio mediante la Ley Sáenz Peña) procuran disciplinar estas indómitas presencias.

\section{FABricar ARgentinos PARA CREAR LA NACión}

En este contexto, las preocupaciones en torno a la "cuestión nacional" se cuelan en las reflexiones de la élite intelectual de la época. Convocada por el mismo Estado a ocupar un lugar fundamental en la empresa nacionalizadora, aboca sus esfuerzos a dar cuenta de los problemas o efectos del proyecto de 1880 . Los relatos que resultaron hegemónicos en el momento histórico al que hacemos referencia, en consecuencia, han contribuido a la producción de un nosotros que, en el caso argentino, ha tramitado de un modo sumamente conflictivo su relación con la figura del migrante externo.

Los discursos de fines del siglo XIX y principios del siglo XX que aquí analizamos pertenecen a autores destacados e influyentes en la escena nacional. Específicamente, nos referimos a las obras Las multitudes argentinas de José María Ramos Mejía, Sociología Argentina de José Ingenieros y La restauración nacionalista, de Ricardo Rojas.

José María Ramos Mejía y José Ingenieros son dos de los máximos representantes de una de las corrientes de pensamiento que emergió como hegemónica, no sólo en Argentina sino en toda América Latina; el positivismo. En el caso argentino, sus exponentes persiguen, con mayor sistematicidad que la de los intelectuales de la llamada Generación del 80, una articulación teórica que permita dilucidar las lógicas del proceso de modernización en ciernes y que encuentra asidero en un entramado institucional - educativo, sanitario, militar y jurídico- organizado desde el Estado. Para el positivismo, conocer los fenómenos y establecer leyes científicas sobre su funcionamiento es clave para poder dominarlos. Por ello, concebido como un movimiento cultural de constitución de la nación, la interpretación del pasado nacional y la búsqueda de las claves para el futuro fueron algunas de sus obsesiones.

De procedencia patricia, el linaje de la familia de José María Ramos Mejía (1849-1914) data de la época colonial. Doctorado en medicina, especializado en patología nerviosa, entre sus múltiples cargos y obras se destacan la creación de la Asistencia Pública de Buenos Aires, de la cátedra de Neuropatología, del Círculo Médico Argentino y del Departamento de Higiene. Ocupó, además, un cargo como diputado entre 1888 y 1892. Sin embargo, su cargo más importante fue la presidencia del Consejo Nacional de Educación entre 1908 y 1912.

En palabras de Terán (1987), Ramos Mejía fue uno de los primeros intelectuales argentinos en ofrecer una lectura de la época que señala como uno de los problemas a resolver la cuestión de la nacionalización de las masas migrantes y la presencia del fenómeno multitudinario. En ese sentido, fue clave su participación en el Consejo Nacional de Educación. La laicización que acompaña la modernidad requiere que las instituciones sean investidas de un poder capaz de asegurar la gobernabilidad, y la élite dirigente debe ser la rectora de este proceso. Desde este cargo, Ramos Mejía diseñó, sistematizó e implementó, desde el Estado y hacia todo el 
territorio argentino, la liturgia patriótica y pedagógica, potente herramienta para neutralizar la influencia tanto de ideologías foráneas de izquierda, potenciales seductoras de las clases trabajadoras, como también de las lealtades hacia la nación de origen. Se trata de una liturgia cuyos objetivos no son de exclusión, sino de asimilación de las masas migrantes. Esta asimilación, no obstante, no oculta la superioridad que adjudica al hogar de linaje criollo por sobre el migrante.

En Las multitudes argentinas, publicado en 1899, Ramos Mejía reflexiona sobre quiénes producen los acontecimientos políticos en el país; la génesis, el papel y el desenvolvimiento de las multitudes en la historia nacional, y las diferencias entre las multitudes urbanas y rurales, entre otros temas. Especial atención dedica en su obra a la cuestión migratoria. Atento a la transformación social producida por la inmigración de masas, realiza una caracterización de la figura del migrante y de los tipos desviados que se basa, sin lugar a dudas, en conceptos provenientes del darwinismo social, como los de lucha por la vida y la supervivencia del más apto. No obstante, es posible hallar en su discurso, al mismo tiempo, una mirada asimilacionista, de "integración paternalista". Aun con contradicciones, complejidades, y peligros, los inmigrantes sí tienen un lugar en la nación y en el proyecto modernizador de 1880. Si bien en Las multitudes argentinas ellos no son el factor del progreso que eran para Sarmiento y la Generación del 37, la educación nacional, con su potencial transformador, junto a la acción del medio argentino, serán las encargadas de permitir la emergencia de una "multitud política" depositaria del sentimiento de nacionalidad.

José Ingenieros es otro - si no el mayor - de los grandes exponentes de la criminología y el positivismo argentinos. Nacido en Palermo (Italia) en 1877, emigró a la Argentina a los ocho años. Médico criminólogo, Ingenieros no posee linaje patricio, capital económico ni político, por lo que parte de su prolífica carrera es fruto de la movilidad social ascendente que estaba experimentando la Argentina de las últimas décadas del siglo XIX. Sin embargo, la emergencia de una figura como la suya debe considerarse no sólo en el marco de los cambios que la sociedad argentina estaba experimentando (modernización, secularización, inmigración) sino también en sintonía con la conformación de un campo intelectual en el sentido bourdieano del término; es decir, como espacio con su lógica y sus relaciones específicas, que se deslindan relativamente de la economía y la política. A diferencia de los escritores gentleman (como los ha llamado Viñas), cuya posición social surge de la posibilidad de que sus capitales heredados sean legitimados en el ámbito intelectual como continuación de su posición económica, a principios del siglo XX comienza a asomar un nuevo tipo de escritor, entre los que es posible ubicar a Ingenieros (pero también a Rojas, como se verá, aunque su origen socioeconómico sea diferente).

Los textos de Ingenieros elegidos para formar parte del corpus pertenecen a su obra Sociología Argentina. Publicada en 1918, reúne producciones del autor en torno a la temática de la nacionalidad argentina y la cuestión migratoria desde la óptica sociodarwiniana de la superioridad de la raza blanca. En esta oportunidad, se trabaja específicamente con la primera parte, "La evolución sociológica argentina", que reúne a su vez textos publicados entre 1887 y 1908 , y con la cuarta, denominada "La formación de una raza argentina”, de 1915.

Hemos señalado que la obra de Ingenieros y de Ramos Mejía no resulta ajena a un determinado clima de época. Tal como señalan Ansaldi y Funes (1994), en el positivismo de principios de siglo XX el empleo de conceptos provenientes del darwinismo social, como hibridismo, atavismo, primitivismo, degeneración y selección dio lugar a procesos de clasificación y jerarquización de poblaciones, que ofrecían lecturas medicalizantes de la sociedad, diagnosticaban patologías y proponían terapéuticas. El racismo, señalan los autores, fue la ideología oficial de las clases dominantes de la época e impregnó los sentidos comunes de toda la sociedad.

Para contextualizar la obra del último autor, Ricardo Rojas, como también la de Ingenieros, resulta ineludible la referencia al clima de época propio del Centenario de la Revolución de Mayo.Por un lado, a los cambios acaecidos en el país fruto del proyecto modernizador, se suma una intensificación de la inquietud que la presencia extranjera en las urbes y la creciente organización del movimiento obrero genera en las élites dirigentes. Así, "el coro de elogios convencionales que solía oírse alrededor del tema de los inmigrantes 
que venían a labrar la fértil tierra argentina, comenzó a apagarse por los recelos que suscitaba la «mala inmigración»" (Romero, 1987, p. 66). Consecuentemente, se produce una escalada represiva y persecutoria que busca sofocar esta organización. En medio de este clima, la preocupación en torno de la nacionalización de las masas migrantes también se profundiza, aunque es posible observar ciertos cambios en esta denominada "reacción nacionalista" y en el lugar que tiene la inmigración en el proyecto de nación. Recordemos que tanto en Ramos Mejía como en Ingenieros, a pesar de la necesidad de controlarla, educarla y aislar sus elementos patógenos, en su carácter blanco y europeo está la clave de la naciente raza argentina. En Ricardo Rojas se apelará a otras fuentes.

Una de ellas es el hispanismo. En esta "generación del 900", a contramano de los hombres de la Independencia, de la Generación del 37 y de la Generación del 80, se produce un intento por recuperar la tradición hispánica (Terán, 1987). Rojas busca el "agente positivo alternativo al inmigrante [en] la cultura indoamericana originaria" (Devoto, 2003, p. 282) al proponer una "fusión de la población nativa, gaucha, criolla de origen español e indígena, con los inmigrantes y sus hijos" (Altamirano y Sarlo, 1997). Si la reacción anticosmopolita y antiinmigrante (o antiobrera) generó, en palabras de Romero (1987), "un movimiento farisaico encubierto de nacionalismo" (p. 68), Rojas, por el contrario, ante su diagnóstico de crisis moral llevó adelante una reacción sentimental. Nacido en Tucumán en 1882, se mudó tempranamente a Santiago del Estero. Su padre, de ascendencia humilde, llegó a ser gobernador de la provincia y luego senador nacional. A su muerte, Rojas, de 16 años, se instaló en Buenos Aires y, siguiendo el mandato familiar, inició sus estudios en la Facultad de Derecho, pero luego los abandonó para dedicarse con intensidad al periodismo, la docencia y la literatura. Llegó a ser Rector de la Universidad de Buenos Aires entre 1926 y 1930. La restauración nacionalista es la obra elegida para formar parte del corpus de textos. Publicada en 1909, surge de una misión oficial que, en 1907, durante la presidencia de Figueroa Alcorta, el Ministerio de Justicia e Instrucción Pública le encarga a Rojas para estudiar los sistemas de educación histórica en las escuelas europeas. El diagnóstico del que parte Rojas y el nuevo nacionalismo que representa implica "algo más que una receta de control social” (HalperínDonghi, 1976, p. 480). La apertura de la Argentina al mundo y los vertiginosos cambios que esta ha experimentado hacen que, en medio de un clima de rivalidad entre países, el sistema de valores dominantes esté guiado únicamente por la conquista del éxito y el lucro individual, sin consideración por objetivos trascendentes y supraindividuales. Ante esta situación, y ante la supuesta pérdida de la cohesión nacional, urge la necesidad de restaurar (¿o construir?) un sentimiento nacional.

En la obra, la necesidad de vigilancia estatal de la educación se vincula con su ataque a las escuelas privadas, consideradas elementos antiargentinos que contribuyen a la disolución nacional. El extranjero debe ser naturalizado, pero su identificación con su antigua nación constituye un rasgo de hostilidad. De ahí la necesidad de una educación nacional homogeneizadora a cargo de una escuela concebida principalmente desde su carácter de institución del Estado, y de la historia, eje en el estudio de las humanidades modernas, como fuerza política capaz de solucionar el excesivo liberalismo reinante en la enseñanza hasta el momento (Ferrás, 2017). Rojas persigue una conciliación entre nativos e inmigrantes sobre la base de la educación patriótica, "en la cual la historia argentina ocuparía un lugar central que serviría para restaurar el «espíritu tradicional» y reconstruir la nacionalidad” (Devoto, 2003, p. 282).Según Ferrás (2017), el nacionalismo de Rojas, integrador de las masas migrantes y reivindicador de la cultura popular y mestiza, se distingue del clima aristocrático que sigue siendo hegemónico en la Argentina del Centenario. De este modo, elige focalizar en el aspecto democratizante de su proyecto, subrayando que puede ser considerado el primer intelectual en "sostener una teoría sobre la identidad nacional distinta a la que contiene la frase los argentinos somos de raza blanca y europea"' (p. 24) en medio de la hegemonía positivista que imaginaba una Argentina que se reflejase en Europa. Para Rojas, la misión cívica del poeta es ensayar una nueva respuesta a la pregunta por la argentinidad que Sarmiento inaugura en Conflicto y armonía de las razas en América. Una de las claves está en la noción de territorio, ya que allí “y no en la etnia, se encarna la historia de la nación, que es única” (Ferrás, 2017, p. 19). Este es considerado elemento orgánico, "sostén material y simbólico en el que reposa el pueblo, 
entendido como población (etnia y lengua) que lo habita" (p. 56), espacio de fusión de las migraciones de América y Europa.

Es importante aclarar que el corpus de textos construido no puede ser concebido como la voz unívoca y uniforme del Estado nación de fines de fines del siglo XIX y principios del siglo XX, pero sí es posible afirmar que su análisis permite rastrear algunos de los principales modos de caracterización de la migración externa que resultaron hegemónicos durante el período histórico seleccionado, coincidente con la etapa de consolidación del aparato estatal, y cuyas huellas son hallables en la actualidad. Este corpus tampoco tiene la intención de representar cabalmente a toda la élite política y cultural de la Argentina de la época a través de la elección de determinados representantes, sino que se considera que su trabajo, con las particularidades de cada caso, fue producido al interior de las esferas del Estado nación o en la cercanía de sus fronteras.

Del mismo modo, tampoco se asume que las representaciones sociales de docentes y directivos actuales sean la transcripción y reproducción directa de aquellas huellas, de aquellos modos históricos de concebir la migración externa, por más persistencia que estas puedan tener. Sin embargo, su análisis permite echar algo de luz sobre cómo se configuran en el presente los vínculos interculturales y qué lugar se otorga al migrante externo en ellos.

\section{LAS REPRESENTACIONES SOCIALES COMO SISTEMAS DURADEROS DE INTERPRETACIÓN}

En este trabajo, y en función de una decisión teórico-metodológica, docentes y directivos son considerados unidad de análisis en tanto agentes socializadores que forman parte de una institución estatal que a diario gestiona la diversidad étnica y nacional, entendiendo esta función como la capacidad de "disponer, organizar y distribuir recursos materiales y actuar sobre personas (...) a partir de decisiones que afectan las voluntades, ideas y/o acciones de esas personas" (Cohen, 2014,p.16).

Sin desconocer que esto no agota sus funciones, y que lo escolar implica una trama compleja en la que confluyen no sólo relaciones y prácticas institucionalizadas, sino también numerosos y variados agentes, interacciones cotidianas, especificidades locales, tradiciones educativas, entre otros (Rockwell, 1997), analizar los discursos de docentes y directivos y dar cuenta de sus representaciones sociales constituye uno de los modos posibles de reconstruir la voz de la escuela como institución del Estado en torno a la figura del migrante externo.

Las representaciones sociales han sido definidas por Moscovici (1979) como una forma de conocimiento, una producción mental social al igual que el mito, la opinión, la ideología y la ciencia, pero diferente de ellos. Se trata de "entidades casi tangibles [que] circulan, se cruzan y se cristalizan sin cesar en nuestro universo cotidiano (...) la mayor parte de las relaciones sociales estrechas, de los objetos producidos o consumidos, de las comunicaciones intercambiadas están impregnadas de ellas"(p. 27).Orientadas por un sentido práctico, su "materia" no es únicamente la experiencia presente sino también elementos provenientes de la historia, la tradición, la educación.

En este análisis en particular, el lugar institucional que ocupan docentes y directivos resulta fundamental en su elaboración dado que estos son abordados en su calidad de agentes de la escuela en tanto institución estatal. No obstante, esto no implica la búsqueda de una especie de intención estatal única y completamente definida que se expresaría en sus discursos, por más gravitación que la institución educativa sea capaz de generar en los agentes que la integran. Sus representaciones sociales están producidas en un contexto en el cual su rol como parte del sistema educativo - a pesar de ser el único que tenemos en cuenta en este análisis, sumado a su condición de nativos- es sólo uno los múltiples que desempeñan en su vida cotidiana. Por lo tanto, no es posible asumir que a través de ellos habla, sin mediaciones, la institución.

Abric (1994) señala que las representaciones funcionan como un sistema duradero de interpretación de la realidad que rige las relaciones entre los individuos con su entorno físico y social, ya que determinará sus comportamientos o sus prácticas. Es este carácter performativo y su potencial clasificatorio el que mayor 
interés reviste en el presente análisis. Asimismo, tal como señala Schütz (2002), si bien la heterogeneidad, la incoherencia y la contradicción son usuales en el conocimiento del mundo social que los sujetos construyen en su vida diaria, este tiende a ser experimentado como claro y congruente, de modo tal que permita interpretar y aprehender los acontecimientos de esta con la menor contrariedad posible. De allí el carácter racional y al mismo tiempo irracional de las representaciones sociales, y la posibilidad de tolerar e integrar contradicciones que parecerían ilógicas (Abric, 1994).

Tener en cuenta este aspecto resulta fundamental para evitar la búsqueda de explicaciones o significados transparentes en ellas. Una de las razones por las cuales las representaciones sociales admiten la contradicción radica en el modo en que su contenido se estructura siguiendo una jerarquía y una ponderación. En primer lugar, cuentan con un núcleo central o estructurante que imprime su carácter y significación a la representación. Se trata del elemento más estable, el que más resiste al cambio. Seguidamente, se distingue un conjunto de elementos periféricos organizados alrededor de este núcleo que hacen posible la concreción (el anclaje de la representación en la realidad mediante términos concretos, comprensibles); la regulación (la adaptación de la representación a la evolución del contexto mediante la incorporación y reinterpretación de información nueva) y la defensa (que evitaque los cambios modifiquen completamente el núcleo central), por lo que en la mutación de dicho conjunto se encuentra la clave de las representaciones sociales, la posibilidad de que el contexto cambie, de que surjan nuevas interpretaciones, nuevos significados, y que el núcleo representacional permanezca estable y las contradicciones sean sostenidas.

Nuestro objetivo es desentrañar qué elementos y significados conviven caótica y contradictoriamente en ellas, reconociendo que los discursos a partir de los cuales reconstruimos las representaciones sociales son prácticas exentas de un significado definitivo y una racionalidad plena, pero integradas por núcleos representacionales que tienden a ser estables y duraderos.

\section{EL MigRANTE COMO INSTRUMENTO}

La intención de este apartado es ofrecer un recorrido por el modo en que la noción de instrumentalidad de la migración, núcleo central de esta categoría, se presenta en los discursos de los representantes de la élite y en los de los docentes y directivos.

Para Ingenieros, el migrante de ultramar, agente de lo que él denomina "segunda colonización europea" (a diferencia de la primera, la hispánica, considerada un lastre y causa de atraso) es el agente modernizador por excelencia. El componente europeo trasladado a estas tierras será capaz de fundar la civilización euroargentina, en tanto "aportó a la nacionalidad elementos casi desconocidos por la primera, esenciales para constituir una raza nueva e iniciar un nuevo núcleo de civilización: el trabajo y la cultura” (Ingenieros, 1946,p. 460). Además, podrá enfrentarse al latifundio que, entre otros factores, impide que el destino de grandeza argentino se materialice, con lo que se concretará la transición de un régimen feudal a uno auténticamente capitalista.

Tal como hemos señalado, el lugar del migrante, del indio y de la herencia hispánica son diferentes según el diagnóstico de Rojas. No obstante, reconoce los beneficios materiales y económicos de la apertura a la inmigración para crear y sostener el proyecto nacionalista.

No olvidemos que, si el país ha abierto sus puertas al extranjero, ha sido por un doble movimiento de patriotismo y de solidaridad humana: necesitábamos crear económicamente la nacionalidad cuya conciencia ya existía en tiempos de la Constituyente, y entregar, en generosa compensación, la tierra virgen al trabajo humano (Rojas, 2011,p. 280).

Hemos señalado que la percepción de la migración europea como portadora del progreso ha calado hondo en el imaginario nacional y se ha constituido en una representación que pervive hasta nuestros días. Y si bien en las representaciones sociales de docentes y directivos es posible hallar un reconocimiento de la similitud de los móviles en las migraciones del siglo XIX y el siglo XX — consideradas tradicionales-y las actuales, 
es posible observar que se otorga mayor valor a aquel migrante que "se arreglaba con lo que tenía" y no sólo no ofrecía resistencia, sino que se mostraba deseoso de integrarse a la sociedad receptora y fundirse con la cultura nacional. Esta imagen idealizada del migrante tradicional se contrapone a la del actual, siempre bajo un manto de sospecha.

Yo creo que migraban por hambruna, porque en la posguerra no había trabajo, venían a buscar trabajo; venían las clases más humildes. Acá, yo creo que tiene cierta similitud: vienen a buscar trabajo, pero hay también un manejo medio mafioso. Yo lo veo al lado de mi casa. Hay un taller en el que trabajan migrantes; y hay una persona que viene con una combi, que también es migrante, y como que domina a ese grupo. Yo no sé si eso se veía tanto en la migración tradicional. (Directora escuela primaria estatal de gestión pública).

Esta aspiración de integración atribuida a la migración tradicional, sin embargo, no suele estar presente en las representaciones sociales sobre los migrantes actuales.

Yo me remito a la época de la gran inmigración ¿̨no? Bueno, las épocas son distintas pero el proyecto, no sé, desde la ley 1420 , ¿no? Esto que contemplaba la inmigración, insertar y hacer argentinos a esa gente que venía. Eran otras épocas (...) eran otras familias, eran padres que colaboraban y lo que se decía en la escuela era válido (...) así era y no se discutía, y el maestro era la autoridad y el ejemplo ¿̨no? (Docente escuela primaria estatal de gestión privada).

"Necesito esto, necesito lo otro"...Capaz que en aquella época...el migrante español o el italiano, o bueno, o los otros...era como que, bueno, se arreglaba con lo que tenía y ahí podía avanzar socialmente con el tiempo (Directora escuela primaria estatal de gestión pública).

La caracterización de la migración tradicional presente en los discursos de docentes y directivos contiene en sí misma una intención prescriptiva ya que define y señala, por oposición, al buen y al mal migrante (Pacecca, 2006). Aportar, agradecer y adaptarse, en tanto subcategorías analíticas de la categoría "el migrante como instrumento", son las tres condiciones que debe cumplir un migrante para ser considerado un sujeto deseable, o al menos tolerable.

\subsection{Aportar}

Este aspecto se encuentra principalmente ligado al mercado de trabajo y a la laboriosidad del migrante. La sociedad receptora se reserva el derecho de definir — en un examen de admisión nunca definitivo, señala Bauman (1998) — cuáles atributos del migrante representan un aporte beneficioso, como también cuándo estos se convierten en un perjuicio. La determinación de este delgadolímite se realiza en función de las propias necesidades, y se deja en segundo plano el lugar del migrante en tanto sujeto portador de sus propios proyectos migratorios, objetivos y anhelos.

Todos tienen derecho a estar acá pero que vengan realmente con una finalidad, con un objetivo: o estudiar o a trabajar, no a robar, no a perjudicar al otro, me parece (Docente escuela secundaria privada).

Ingenieros, por su parte, enfatiza la superioridad del trabajador extranjero por sobre el nativo y el invaluable aporte que su presencia significa en el territorio argentino.

La capilaridad social ha permitido el encumbramiento del proletariado inmigratorio, cuyas aptitudes para el trabajo son infinitamente mayores que las del proletariado criollo, educado sobre las huellas de la colonización española (Ingenieros, 1946,p. 66).

Mientras que Ramos Mejía, a pesar del atraso evolutivo que le adjudica, considera que su presencia implica un aporte fundamental puesto que su laboriosidad, moldeada por la influencia del medio, permitirá la emergencia de una raza nueva.

Crepuscular, pues, y larval en cierto sentido, es el estado de adelanto psíquico de ese campesino, en parte, el vigoroso protoplasma de la raza nueva, cuando recién pisa nuestra tierra (Ramos Mejía, 1899,p. 291). 
Ante la inevitabilidad de la migración, Rojas expresa claramente cuáles son los atributos que debe tener un migrante para que resulte favorable incorporarlo: la laboriosidad y la intención de argentinizar a sus hijos. De ahí que elija al migrante italiano, aunque al mismo tiempo perciba alarmado su presencia cada vez más numerosa.

De las inmigraciones que pueden venirnos, es la mejor de todas la italiana (...) el italiano tiene el prestigio de su historia: es el mayorazgo de la latinidad a la cual pertenecemos, y muestra aún los restos de una antigua dominación española. Fuera de ese abolengo es para nosotros el que trabaja con amor los campos y da hijos más argentinos, dos características excelentes, cuando necesitamos combatir la centralización urbana y la prolongación en la prole criolla de prejuicios ancestrales, ajenos a nuestra propia nacionalidad: a todo aquel que nazca en territorio argentino, debe educársele para ser un ciudadano argentino (Rojas, 2011,p. 280).

El "ímpetu de sangre nueva", traducido como la aspiración del migrante a una vida mejor, al progreso material y social para ellos y su descendencia, también es positivamente valorado por los docentes y directivos.

-Para los bolivianos, yo diría que son muy trabajadores.

-Trabajan mucho tiempo en los talleres de costura.

-Y muy buenos modales. Y aparte son de los pocos que trabajan la tierra, que con lo que vos decías, se perdió el trabajo en la tierra.

¡¡Sabés cómo trabajan! ¡Todo el día, la cintura! (Docentes escuela secundaria estatal de gestión pública).

Que el migrante sacrificado y portador de “cultura del trabajo” tenga intención de superación, de mejorar sus condiciones de existencia, siempre como fruto de su trabajo y su esfuerzo, es considerado un atributo sumamente positivo, porque de algún modo esa cultura del trabajo implica un aporte a la nación, como la laboriosidad y predisposición a integrarse que señala Rojas a propósito de la migración italiana.

Hay que tener en cuenta la personalidad según el país de origen. Un boliviano va a tener una raíz temperamental distinta a la de un peruano, que ya viene con intenciones más de superación, más logros...Aparentemente tienen una personalidad mucho más fuerte que la del boliviano (...) El peruano quizás tenga una personalidad con deseos más de superación, o más parecido al porteño, digamos. (Docente escuela primaria estatal de gestión pública).

Incluso es considerado justo, desde una lógica meritocrática, que el migrante que se esfuerza y dedica su vida al trabajo, con sacrificio y tenacidad, reciba un beneficio. Ahora bien: el conflicto surge cuando los anhelos y expectativas del migrante superan el límite de ambición legítimo definido por la sociedad receptora. Allí sus intenciones son consideradas oportunistas, movidas por el deseo de sacar demasiado rédito, de obtener una ventaja por sobre el nativo.

Yo creo que el oportunismo del que viene de afuera (...) muchas veces viene con la intención de sacar provecho. Los que vienen de niveles muy bajos de Bolivia, Perú, vienen a beneficiarse porque hay plan social, porque hay esto, porque hay lo otro, porque la educación es gratuita, muchos vienen a estudiar. Los chinos, los coreanos vienen porque acá no se les cobra impuestos para poner un negocio (...) muchos vienen a aprovechar las circunstancias. Si bien entiendo cuál es el contexto de ellos y lo veo bien también, me parece que a veces hay un abuso, y eso molesta porque uno está luchando para salir adelante y ve que a otros extranjeros se les dan otras posibilidades y todo se les hace más fácil (Docente escuela secundaria estatal de gestión pública).

Al cruzar este límite, la imagen del migrante trabajador, perseverante y dedicado se borronea y emerge la del migrante avaro, codicioso, explotador e incluso simulador.

Está esa que renguea cuando va entre los autos y cuando cambia el semáforo se apura y camina perfectamente. La vi yo, no me lo contaron. (...) En Sucre y Juramento hay una mamá que les saca las zapatillas a los chicos, las mete en la mochila y les hace pedir descalzos (Docente escuela primaria estatal de gestión privada).

De un modo similar, la idea del migrante que ha expandido sus medios de subsistencia y mejorado sus condiciones de vida gracias a la Argentina, y que luego se convierte en un avaro y mezquino, también se encuentra presente en la figura del burgués de otra parte (burguesaureus) de Ramos Mejía. 
Tipo esencial y excesivamente conservador, de cierta modestia previsora porque procede de la avaricia y del terror al descubrimiento de la gran fortuna amasada a costa de su salud tal vez (...) Representa, entre nosotros, el burgués de otras partes, el improvisado millonario nacido del sortilegio de la lotería y surgido del sembradío inmenso de la colonia o del humeante montón de la tierra fecundada por su noble trabajo. Pero una vez que ha tomado su colocación no tiene más programa en la vida que guardar su dinero, defenderlo de la caridad y del patriotismo que alguna vez golpea sus puertas, oprimirlo contra su pecho para que no abulte (...). Almas desasidas de las cosas ideales que no dan plata, lo mismo es para ellos el despotismo que la libertad, siempre que le conserve su dinero (Ramos Mejía, 1899,p. 308).

Aquí vemos cómo el afán de progreso, el sacrificio y la dedicación al trabajo, considerados atributos positivos, son leídos como aspectos negativos. El migrante que se ha enriquecido "a costa incluso de su salud", y que esconde su fortuna por miedo a ser descubierto, ya no representa un aporte para la nación. Se trata de un sujeto peligroso pues su único móvil en la vida es el dinero, se encuentra desprovisto de ideales y, fundamentalmente, no siente amor por la patria que le dio cobijo. Es deseable, entonces, que el migrante dedique su vida al sacrificado trabajo, pero que no se convierta en un sujeto tacaño enriquecido a costa de la nación.

Los paraguayos trabajan y amarrocan. No gastan, no gastan, no gastan. Le mandan la plata a los de allá. Cada vez traen más paraguayos (...) también yo los veo...ventajeros a los paraguayos (Docente escuela primaria estatal de gestión privada).

\subsection{Agradecer}

El buen migrante debe ser capaz de valorar lo que le brinda la Argentina, demostrando a cambio su lealtad, fidelidad y respeto. Las razones por las cuales el migrante decide venir a la Argentina se relacionan íntimamente con este aspecto.

También tiene que ver la pobreza que hay en Bolivia y en Perú. La posibilidad de estar en un país como Argentina, que tiene las fronteras abiertas, que les da la posibilidad de tener salud y educación...Es una tentación muy grande (Docente escuela primaria estatal de gestión privada).

Ante países signados por la pobreza, la carencia, y el atraso, los docentes y directivos señalan que la Argentina se erige como una suerte de tierra prometida, pues ofrece cobijo, trabajo, educación, salud, todos aspectos capaces de brindar al migrante un mejor porvenir, aunque sea en comparación con el de su país de origen.

Ante esta situación, el buen migrante ofrece su agradecimiento y respeto, en este caso, a las autoridades escolares.

Pero por parte de los padres, hay un reconocimiento hacia el docente que no hay de la gente de acá. El respeto, la aceptación de lo que la maestra le dice. Si lo aconseja, él enseguida toma al pie de la letra y hace (Docente escuela primaria estatal de gestión privada).

Ramos Mejía también hace referencia en su obra al agradecimiento y la lealtad migrante, a tal punto que en el siguiente pasaje caracteriza al niño migrante como depositario del sentimiento de la nacionalidad.

Ese niño vagabundo y curioso, eterno ocupante de la calle, es el que aplaude con más calor las escuelas de cadetes, que con encantadora gravedad desfilan en los días de la patria, el que viva con bullicioso entusiasmo la bandera haraposa del viejo y glorioso batallón, el que acompaña a la tropa más lejos, el que no falta a la lista, el que se asocia con la más candorosa y sincera decisión a todas las cosas populares en que está el pabellón y el uniforme (Ramos Mejía, 1899,p. 299).

Respeto, lealtad, valoración del país: acciones que acompañan el sacrificio y empeño que observamos en la subcategoría precedente, cuya contracara es la pasividad, la sumisión, la vergüenza y la timidez. El migrante sacrificado y laborioso es también aquel incapaz de reclamar y articular demandas, y que acepta cualquier condición que el país receptor le impone. 
Me asombra la dócil plasticidad de ese italiano inmigrante. Llega amorfo y protoplasmático a estas playas y acepta con profética mansedumbre todas las formas que le imprime la necesidad y la legítima ambición (Ramos Mejía, 1899,p. 293).

-Con respecto al trabajo, para conseguirlo, como en el caso de la gente de Perú, de Bolivia, o sea, las condiciones que tienen acá no son dignas tampoco, pero les sirve para...consiguen más fácil.

-Y sí, porque un argentino no hace cosas que ellos harían (Docentes escuela secundaria estatal de gestión privada).

Si el buen migrante es aquel que se limita a aceptar lo que el país le otorga, brindando a cambio su noble agradecimiento, el mal migrante, por el contrario, es aquel que plantea exigencias e impone condiciones al país receptor.

A mí lo que me pone, me saca mal, es cuando exigen cosas en virtud de ser extranjeros y es común que pase eso (Docente escuela secundaria estatal de gestión privada).

Es posible encontrar en el relato de docentes y directivos distintos niveles mediante los cuales consideran que se expresa esta exigencia migrante. Por un lado, refieren a una autovictimización que les permite obtener algo a cambio.

Allá es todo ir a comer. Ir a pedir hoja, lapicera, lápiz. Dependen. Ya directamente eso es pedir. Cambió todo, digamos. Yo trabajo en la zona y en Florencio Varela yo también trabajo: es pedir, un pedir constante. Ellos no quieren, digamos, están acostumbrados. La otra vez estaba hablando en una reunión de profesores y decían: "Estos chicos son los de los padres que tienen que pedir”. Ellos están en la casa, la cultura, digamos, es pedir (Docente escuela secundaria estatal de gestión pública).

Esta imagen evoca de algún modo la del simulador, en tanto la carencia y sumisión que el migrante expresa sería un artilugio para recibir un beneficio. Por otro lado, el más extremo y opuesto a la noción de sumisión, encontramos la imagen del migrante que exige de modo abusivo.

\begin{abstract}
-No nos olvidemos, vuelvo a lo mismo: cuando vinieron los antepasados también trabajaban como bestias, los italianos, los españoles, nadie los ayudaba, no les daban Plan Trabajar. Poner el lomo y trabajaban para, bueno, conseguir lo que podían.

-Y lo que yo veo es como que ahora, mucho de estas migraciones es como que exigen o piden o se sienten discriminados, o exigen al gobierno, o piden algo, no sé. Y yo digo, antes, cuando mi abuelo vino de España, ¿qué le iba a pedir al gobierno? Gracias que trabajaba (...) Había más cultura del trabajo y esfuerzo, hoy se quiere todo fácil y ya...(Docentes escuela secundaria estatal de gestión privada).
\end{abstract}

\title{
5.3 Adaptarse
}

Este es uno de los puntos nodales de la categoría que aquí presentamos pues remite a una concepción que se contrapone a otro modo recurrente de caracterizar al migrante externo — cuyo análisis excede los objetivos de este artículo-, vinculado a suesencia y a la imposibilidad de cambio,pero que sin embargo convive con la idea de adaptación tanto en los discursos como en las representaciones sociales. En esta subcategoría podremos observar concretamente qué implicancias tiene el papel adjudicado al territorio y a la influencia del medio en la caracterización del migrante externo.

Para Ramos Mejía, estamos en presencia de una tabula rasa, un ser sin forma definitiva preestablecida que gracias a la influencia del medio (entre otros factores) es capaz de ser moldeado.

Pero el medio opera maravillas en la plástica mansedumbre de su cerebro casi virgen. La luz de este cielo despierta la dormida actividad de las imágenes visuales; el ruido primero y el sonido después, el color variado, las formas multiplicadas de las cosas, y esa secreta inclinación y competencia elemental de la raza por el arte, no en su sentido grandioso, sino por alguna de sus más humildes manifestaciones (aunque no por eso menos útiles) que se traducen en las artes manuales y domésticas que dan de comer y facilitan la vida, concurren a ese fin (Ramos Mejía, 1899,p. 292).

Si Ramos Mejía considera al migrante un depositario del sentimiento de la nacionalidad y observa esperanzado el modo en que este puede ser "argentinizado" es porque considera, justamente, que lo que porta 
de origen es apenas su potencial laboriosidad y su maleabilidad. Esto lo convierte en un futuro depositario del contenido que se elija "depositarle". De allí la peligrosidad de las multitudes sin guía, que "hace hoy la independencia de América y mañana la tiranía de Rosas o la «anarquía de 1820»” (p. 114). Y de allí, también, la importancia de que sea el Estado y sus instituciones, como la escuela, la que tenga a su cargo la tarea de realizar este "moldeado argentinizador". El autor describe al migrante, entonces, como un sujeto dispuesto no sólo a adaptarse sino también a llevar adelante las tareas y labores que sean necesarias para subsistir.

Ellos son cocheros, después de su aprendizaje doloroso de chichones y espolonazos violentos contra los otros coches, de contravenciones y multas, que les aguzan el ingenio (...) ellos son mayorales y conductores, y hasta los picantes dicharachos de la compadrería urbana y callejera, suelen brotar de sus labios con gracia exótica para aquel cerebro todavía burdo y acuoso; ellos son, en suma, todo lo que dé medios de vivir y prometa un porvenir, remoto si queréis, pero seguro. Con deciros que en ciertos trabajos hasta al gaucho han desalojado (Ramos Mejía, 1899,p. 294).

La idea del migrante como aquel que llega sin nada más que su fuerza de trabajo es hallable en las representaciones sociales de los docentes cuando señalan que los estudiantes de origen migrante llegan a la escuela y empiezan "de cero".

Es un barrio que por las características que tiene parecería que se han instalado muchos coreanos, japoneses, bolivianos. Se integran bastante bien a las clases. Chicos que, por ejemplo en primer año tengo cuarenta alumnos y quizás un chico que recién ingresa viene de Bolivia, así que el primer día viene de clase, viene de Bolivia. $\mathrm{O}$ sea, un contexto totalmente diferente, una población diferente, una cultura diferente y se le incorpora de cero a un colegio secundario, de Capital. Es muy difícil, no saben escribir bien (Docente escuela secundaria estatal de gestión privada).

Según la imagen del migrante como tabula rasa, los conocimientos, el idioma y todos aquellos saberes que se portan desde origen son inferiorizados o directamente anulados, lo que hace del sujeto que arriba alguien desprovisto de todo. "De cero" entonces, implica la carencia en todo sentido: material, simbólica e intelectual. Si bien en la cita precedente esta carencia es representada como un problema, veremos al mismo tiempo el papel atribuido al medio en su moldeado. Este venir sin nada más que sus manos es lo que los hace aceptar y adaptarse a cualquier condición laboral, como hemos visto.

Para Ingenieros, de un modo distinto que para Ramos Mejía, la raza argentina en formación tiene como protagonista al migrante, pero porque este es portador de características que aportan a la nacionalidad elementos novedosos y sumamente beneficiosos, y que trasplantados al suelo argentino son incluso capaces de contrarrestar la primera migración.

La mejor parte del territorio pastoril fue ocupada por argentinos descendientes de los colonizadores. A los gauchos se sustituyeron los colonos, a las carretas, los ferrocarriles, a los comandantes de campaña, los maestros de escuela; una población alfabeta, laboriosa y democrática fue creciendo en reemplazo de la analfabeta, anarquista y feudal. Esta segunda colonización europea aportó a la nacionalidad elementos casi desconocidos por la primera, esenciales para constituir una raza nueva e iniciar un nuevo núcleo de civilización: el trabajo y la cultura (Ingenieros, 1946,p. 460).

Rojas, por su parte, en su afán asimilacionista, considera que la influencia territorial, la fuerza caracterizadora del territorio, es capaz de inculcar el orgullo criollo.

Esta manera de nacionalismo quiere, por el contrario, tanto como lo querían Alberdi o Sarmiento, campeones aquí del cosmopolitismo, que vengan sus capitales, sus hombres y sus ideas. Pero quiere que una hábil política económica radique en el país el mayor beneficio de esos capitales. Quiere que el hijo del inmigrante sea profundamente argentino, por el discernimiento cívico que le dé nuestra educación; que razone su patriotismo; que haga fecundo para la nación el instinto y orgullo criollos con que ya lo diferenciara de sus padres la poderosa influencia territorial (Rojas, 2011,p. 222).

En la adaptabilidad migrante conviven dos aspectos. El migrante que bajo la influencia territorial es transformado y adaptado al medio, tal como hemos señalado a propósito de Ramos Mejía y la idea de tabula rasa, y el migrante que también es capaz de dejar su impronta y de ese modo, dar lugar a un producto nuevo, la argentinidad. En el caso de Ingenieros, esta implica no únicamente la influencia que el medio ejerce sobre el migrante, sino también la síntesis que se produce sobre la base de aquella en conjunción con su aporte. 
Una nueva raza argentina se está formando por el conjunto de variaciones sociales y psicológicas que la Naturaleza argentina imprime a las razas europeas adaptadas a su territorio (...) Está en formación. En la medida en que ella prospera y se consolida, va creciendo el sentimiento colectivo de la nacionalidad: la consolidación moral para la realización de ideales comunes (Ingenieros, 1946,p. 463).

El medio, en este caso, es capaz de "volver argentinos" a los migrantes, o al menos de borrar parcialmente aquel vestigio de su origen.

- Los padres coreanos son de pegar...y tienen un nivel de exigencia...A veces han venido a pedir disculpas porque no han estudiado y ofendieron al maestro. Tiempos atrás, eh.

- Sí, ya son criollitos los coreanos de ahora. Pero los primeros coreanos...

- Yo creo que varía en extranjero de hace poca data, de extranjero de años de residencia. El extranjero que lleva años de residencia (...) adquirió todas las mañas y es un porteño más (Docentes escuela primaria estatal de gestión privada).

La eliminación de este "rastro étnico" es aún más completa en el hijo del migrante y en todas las generaciones que le suceden. Tanto Rojas como Ramos Mejía e Ingenieros otorgan un rol fundamental a esta figura, pues en ella se conjugan en su máxima expresión los caracteres propios del origen nacional de sus padres junto con la influencia que el medio es capaz de ejercer en su constitución, uno de cuyos productos es la emergencia de un sentimiento nacional.

Hay que observar los niños de los últimos grados para ver cómo de generación en generación, se va modificando el tipo del inmigrante hecho gente (Ramos Mejía, 1899,p. 302).

La primera generación es, a menudo, deforme y poco bella hasta cierta edad; parece el producto de un molde grosero, los primeros vaciamientos de la fundición de un metal noble, pero todavía lleno de engrosamientos y aristas que el pulimento posterior va a corregir. Hay un tanto por ciento de narices chatas, orejas grandes y labios gruesos: su morfología no ha sido modificada aún por el cincel de la cultura. En la segunda, ya se ven las correcciones que empieza a imprimir la vida civilizada y más culta que la que ha traído el labriego inmigrante. El cambio de nutrición, la influencia del aire y de la relativa quietud del ánimo por la consecución fácil del alimento y de las supremas necesidades de la vida, operan su influjo trascendental (Ramos Mejía, 1899,p. 301).

Un "sentimiento nacional" se forma y define poco a poco en las clases más ilustradas, refundiéndose en él los antiguos "sentimientos localistas" de la época feudal. Esa unificación mental de los descendientes de la antigua inmigración conquistadora, coincide con un fenómeno paralelo, aunque más importante numéricamente, fácil de observar en los descendientes de la nueva inmigración colonizadora, que son ardientemente argentinos y asimilan rápidamente los rasgos esenciales de la mentalidad nacional (Ingenieros, 1946,p. 72).

Pero el inmigrante europeo de hoy es como el de la época colonial: vuelve a su tierra o muere en la nuestra; es algo que pasa. Lo que perdura de él es su hijo y la descendencia de sus hijos; y éstos, criollos hoy como en tiempos de la independencia, tienen ese matiz común que impóneles el ambiente americano (Rojas, 2011,p. 220).

Esta acción caracterizadora del territorio americano en la que Rojas asienta las bases de su proyecto nacionalizador, este sentimiento de amor a la patria que Ramos Mejía considera que el suelo argentino es capaz de despertar en el migrante, no actúan, sin embargo, de manera espontánea e involuntaria. Es la escuela la encargada de asimilar y argentinizar al migrante.Sin embargo, es necesario que no lleve adelante su labor de manera aislada, sino que exista una tendencia nacionalizadora en toda la sociedad. El migrante debe desenvolverse en un entorno donde el componente nacional prime sobre el resto.

¿De qué servirá, asimismo, que el maestro enseñe su gramática, y diga que el castellano es el idioma del país, si el alumno, al regresar de la escuela, ve las aceras llenas de letreros en francés, en inglés, en alemán? Los comerciantes e industriales pueden ser extranjeros; pero cuando vienen a hacer su granjería en nuestro territorio, tenemos el derecho de imponerles la lengua del país, que es uno de los signos de nuestra nacionalidad (Rojas, 2011,p. 271).

El migrante asimilado, que siente amor y respeto por la patria que lo recibió y que, sin abandonar completamente "su cultura", no se resiste a adquirir los caracteres que le ofrece el medio argentino, surge entre los docentes y directivos como la culminación de la imagen del buen migrante, el ejemplar perfecto de aquel mítico integrante del "crisol de razas" alrededor del cual se estructura nuestra identidad nacional. 
¿Vos sabés qué lindo es decir “Miren, este chico se educó acá, aprendió con nosotros, puso toda su voluntad acá, se mató, por eso tenemos el orgullo de que un extranjero lleve la bandera”? (Docente escuela primaria estatal de gestión pública).

\section{A MODO DE CIERRE}

Hemos indicado tres requisitos que el migrante que aspira a lograr su admisión a la comunidad nacional debe cumplir: aportar lo que la sociedad receptora necesita, agradecerle con lealtad y respeto lo que ella le ofrece, y adaptarse a las condiciones que el medio le impone.

En la caracterización de la figura del migrante que atraviesa estas tres condiciones - y que, tal como hemos señalado, nos permiten definir al buen y al mal migrante -observamos que los diversos atributos que se le asignan parecieran emanados de su propia sustancia, como si el origen fuera responsable de imprimir en él determinados rasgos. Sin embargo, las características "reales" que porta el migrante no resultan fundamentales en su descripción, en tanto un mismo atributo puede ser evaluado de forma diferencial según la funcionalidad que comporte para la sociedad receptora en un momento dado. Así, la abnegación y el sacrificio en el trabajo pueden ser considerados una virtud admirable, para convertirse en rasgos negativos que denotan avaricia, mezquindad o competencia desleal cuando las pretensiones del migrante no coincidan con las que la sociedad receptora le impuso como límite válido.

Por consiguiente, y a modo de ejemplo, los bolivianos serán en algunos casos considerados personas sumisas, respetuosas, calladas, trabajadoras, tímidas, mientras que, en otros casos, oportunistas y vagos. Análogamente, los orientales (categoría que aglutina de manera casi indiferenciada a chinos, coreanos y japoneses) serán catalogados como trabajadores, de rápido aprendizaje, inteligentes, tenaces, pero también como ventajeros, calculadores y estrategas. Este modo de caracterizar al migrante externo puede vincularse con una de las funciones de las representaciones sociales: la de orientar y proveer un sistema de anticipaciones y expectativas. Abric (1994) afirma que la representación social "no depende de la evolución de una interacción, la precede y determina” (p. 16). Consecuentemente, la caracterización que los docentes y directivos realizan de los migrantes en el aula (y en la sociedad en general) está fundada en sus prejuicios y representaciones previas, más que en aquellas características "reales". De este modo, conocer de antemano cómo los migrantes "son" permite anticipar qué debemos esperar de ellos.

En síntesis, el punto fundamental del núcleo representacional que procuramos describir aquí radica en que la caracterización del migrante, sea positiva o negativa, siempre se realiza desde una perspectiva - la de la sociedad receptora - que le otorga un valor o un desvalor según cuan beneficiosa y funcional se considere su presencia, y que esta caracterización se emplea de diversos modos para explicar y justificar su tratamiento diferencial. En tanto el migrante es ajeno a la sociedad nacional, es ella la que debe evaluar su utilidad y exigir una serie de condiciones, siempre prestas al cambio, para su admisión. La sociedad receptora se reserva así el derecho de asignar la etiqueta al migrante eludiendo casi cualquier referencia a las condiciones de producción de aquella, con lo que perpetúa la desigualdad del vínculo intercultural. Este tiende a constituirse como una relación social de dominación en la que nativos y migrantes se encuentran en jerarquías diferenciales. Y ello porque la evaluación del migrante se realiza a partir de un código moral hegemónico que, constituido a la par de la conformación del Estado nación argentino, ha ido estableciendo los criterios de normalidad y desviación, de ciudadano y de extraño. Este código supone la existencia de una comunidad nacional integrada, homogénea y homogeneizante, portadora de una "naturaleza moral unificada" (Benhabib, 2005). En el caso argentino, se ha manifestado a través de una alerta constante frente a la diversidad étnica y nacional por la potencial amenaza - o al menos trastocamiento- que esta puede representar para la integridad nacional (Cohen, 2009). Sin intención de establecer relaciones mecánicas y deterministas, el rastreo de las huellas de modos históricos de concebir la migración que perviven en la actualidad constituye un modo de analizar cómo aquel código se reactualiza y qué trazos y señales del pasado encontramos en el presente, alejándonos de una transposición directa y falaz. 


\section{REFERENCIAS}

Abric, J. (1994). Prácticas sociales y representaciones. México D.F.: Ediciones Coyoacán.

Altamirano, C. y Sarlo, B. (1997). Ensayos argentinos. De Sarmiento a la vanguardia. Buenos Aires: Ariel.

Ansaldi, W.y Funes, P. (1994). Patologías y rechazos. El racismo como factor constitutivo de la legitimidad política del orden oligárquico y la cultura política latinoamericana. Cuicuilco. Revista de la Escuela Nacional de Antropología e Historia.1(2). Recuperado de http://geshal.sociales.uba.ar/wp-content/uploads/sites/110/2015/01/FUNESy-ANSALDI-Patolog\%C3\%ADas-y-rechazos.pdf

Bauman, Z. (1998). Modernidad y ambivalencia. En J. Beriain (Comp.), Las consecuencias perversas de la modernidad (pp. 73-119). Barcelona: Antrophos.

Bertoni, A. (2001). Patriotas, cosmopolitas y nacionalistas. La construcción de la nacionalidad argentina a fines del siglo XIX. Buenos Aires: Fondo de Cultura Económica de Argentina.

Briones, C. (2004). Construcciones de aboriginalidad en Argentina. Bulletin de la Societe Suisse Des Americanistes, 68, 73-90. https://ri.conicet.gov.ar/bitstream/handle/11336/82659/ CONICET_Digital_Nro.7e6f2fea-0a76-482b-88f7-f55282f73aef_A.pdf?sequence=2\&isAllowed=y

Cohen, N. (2009). Una interpretación de la desigualdad desde la diversidad étnica. En N. Cohen (Comp.), Representaciones de la diversidad: trabajo, escuela y juventud (pp. 11-29).Buenos Aires: Ed. Cooperativas.

Cohen, N. (2011). Cohesión social, diversidad cultural y pobreza: Hacia una convivencia compleja. En N. Cohen y C. Barba Solano (Coords.), Perspectivas criticas sobre la cohesión social: Desigualdad y tentativas fallidas de integración social en América Latina (pp. 87-106). Buenos Aires: CLACSO. Recuperado de http://biblioteca.clacso.edu.ar/ ar/libros/clacso/crop/BarbaSolano-Cohen.pdf

Cohen, N. (2014). Dominación y migraciones externas. Boletín Onteaiken, 17. Recuperado de http:// onteaiken.com.ar/ver/boletin 17/art-cohen.pdf

Corbin, J. y Strauss, A. (2002). Bases de la investigación cualitativa. Técnicas y procedimientos para desarrollar la teoría fundamentada. Medellín: Universidad de Antioquia.

De Lucas, J. (2002). La herida original de las políticas de inmigración. A propósito del lugar de los DD.HH. en las políticas de inmigración. Isegoría, 26, 59-84.

Devoto, F. (2003). Historia de la inmigración en la Argentina. Buenos Aires: Sudamericana.

Ferrás, G. (2017). Ricardo Rojas: nacionalismo, inmigración y democracia. Buenos Aires: Eudeba.

HalperínDonghi, T. (1976). ¿Para qué la inmigración? Ideología y política inmigratoria y aceleración del proceso modernizador: el caso argentino (1810-1914). Jahrbuch für Geschichte von Staat, Wirtschaft und Gesellschaft Lateinamerikas, 13, 437-489. Recuperado de http://sgpwe.izt.uam.mx/files/users/uami/mcheca/

Jahrbuch_fr_Geschichte_Lateinamerikas_Anuario_de_Historia_de_America_Latina_Para_qu_la_inmigracin _Ideologa_y_poltica_inmigratoria_y_aceleracin_del_proceso_m.pdf

Ibáñez, J. (1992). Más allá de la sociología. El grupo de discusión: técnica y crítica. Barcelona: Siglo XXI.

Ingenieros, J. (1946). Sociología Argentina. Buenos Aires: Losada.

Moscovici, S. (1979). El Psicoanálisis, su imagen y su público. Buenos Aires: Huemul.

Novick, S. (2008). Migración y política en Argentina. Tres leyes para un país extenso (1876-2004). En S. Novick (Comp.), Las migraciones en América Latina (pp. 131-151). Buenos Aires: Catálogos. Recuperado de http:// biblioteca.clacso.edu.ar/ar/libros/grupos/novick/novick.pdf

Oszlak, O. (2018). La formación del Estado argentino. Orden, progreso y organización nacional. Buenos Aires: Ariel.

Pacecca, M.I. (2001). Migrantes de ultramar, migrantes limitrofes. Politicas migratorias y procesos clasificatorios. Argentina, 1945-1970. Informe final del concurso Culturas identidades en América Latina y el Caribe. Programa Regional de Becas CLACSO. Recuperado de http://bibliotecavirtual.clacso.org.ar/ar/libros/becas/2000/ pacecca.pdf

Pacecca, M. I. (2006). Migraciones e Interculturalidad. En A. Ameigeiras y E. Jure (Comps.), Diversidad cultural e interculturalidad (pp. 277-280). Buenos Aires: Prometeo.

Ramos Mejía, J. (1899). Las multitudes argentinas. Buenos Aires: Felix Lajouane Editor. 
Rockwell, E. (1997). De huellas, bardas y veredas: una historia cotidiana en la escuela. En E. Rockwell (Coord.), $L a$ escuela cotidiana (pp. 13-57). México, D. F.: Fondo de Cultura Económica.

Rojas, R. (2011). La restauración nacionalista: informe sobre educación. Buenos Aires: UNIPE.

Romero, J. L. (1987). Las ideas en la Argentina del siglo XX. Buenos Aires: Ediciones Nuevo País.

Romero, L. (2004). La Argentina en la escuela. Buenos Aires: Siglo Veintiuno editores.

Sayad, A. (2008). Estado, nación e inmigración. Apuntes de investigación del CECYP,13, 101-116. Recuperado de http://apuntescecyp.com.ar/index.php/apuntes/article/view/122/107

Schütz, A. (2002). El forastero. En E. Terrén (Comp.),Razas en conflicto. Perspectivas sociológicas (pp. 144-156). Barcelona: Anthropos.

Terán, O. (1987). Positivismo y nación. Buenos Aires: Puntosur.

Terán, O. (2008). Historia de las ideas en la Argentina. Diez lecciones iniciales, 1880-1980. Buenos Aires: Siglo XXI Editores Argentina.

Viñas, D. (1964). Literatura argentina y realidad politica. Buenos Aires: Jorge Álvarez Editor.

\section{Notas}

[1] Si bien excede los objetivos de este artículo, un análisis comparativo de la legislación migratoria en la Argentina constituye una de las maneras de encarar un estudio de estas características. Al respecto, el trabajo de Novick (2008) ofrece algunas claves sobre los modos históricos de caracterización y concepción de la migración desde las instancias oficiales y los debates suscitados en torno a su presencia.

[2] La categoría que presentamos en este artículo surge de la investigación realizada para una tesis de la Maestríaen Investigación en Ciencias Sociales (Facultad de Ciencias Sociales - UBA) titulada "Las puertas entreabiertas. El otro en la identidad nacional: discursos históricos, escuela y migración”, defendida en agosto de 2021. Mediante la indagación de las huellas históricas e ideológicas de discursos de la élite política y literaria de fines de siglo XIX y principios de siglo $\mathrm{XX}$ en las representaciones sociales de docentes y directivos del AMBA en la actualidad, se construyó un conjunto de categorías acerca de la identidad nacional y la figura del migrante externo, una de las cuales remite a la instrumentalidad de la figura del migrante. Una versión preliminar de este análisis fue presentada en elCongreso Internacional de la Latin American StudiesAssociation (LASA) realizado en mayo de 2021.

[3] Los grupos de discusión fueron realizados en el marco del Proyecto UBACyT "La discriminación hacia el extranjero como táctica de disciplinamiento social” (IIGG - FSC - UBA), bajo la dirección del Dr. Néstor Cohen, mientras que las entrevistas en profundidad, en el marco del Proyecto de Reconocimiento Institucional (FSC - UBA) "Segregación social de los migrantes externos regionales: una aproximación comparativa de las representaciones sociales en las escuelas de la CABA", bajo la dirección de la Dra. Romina Tavernelli y la codirección de la Dra. Anahí González.

[4] En este análisis, centrado en la figura del migrante externo, no se desconoce que el relato sobre la diversidad y la interculturalidad en la Argentina abarca también a otras figuras marcadas étnicamente, como el indio, el negro y el gaucho, entre otros. Para un análisis sobre el modo de triangulación entre los signos indios, inmigrantes y criollos que dio lugar a la constitución de un determinado “crisol de razas” en la Argentina, ver Briones (2004). 